The Journal of Laryngology \& Otology

http://journals.cambridge.org/JLO

Additional services for The Journal of Laryngology \& Otology:

Email alerts: $\underline{\text { Click here }}$

Subscriptions: $\underline{\text { Click here }}$

Commercial reprints: $\underline{\text { Click here }}$

Terms of use : $\underline{\text { Click here }}$

\title{
Rehabilitation of the paralysed face: results of facial nerve surgery
}

Shakeel R. Saeed and Richard T. Ramsden

The Journal of Laryngology \& Otology / Volume 110 / Issue 10 / October 1996, pp 922 - 925

DOI: 10.1017/S0022215100135364, Published online: 29 June 2007

Link to this article: http://journals.cambridge.org/abstract_S0022215100135364

How to cite this article:

Shakeel R. Saeed and Richard T. Ramsden (1996). Rehabilitation of the paralysed face: results of facial nerve surgery. The Journal of Laryngology \& Otology, 110, pp 922-925 doi:10.1017/S0022215100135364

Request Permissions : $\underline{\text { Click here }}$ 


\title{
Rehabilitation of the paralysed face: results of facial nerve surgery
}

\author{
Shakeel R. SAeEd, F.R.C.S. (ORL), Richard T. RAmSden, F.R.C.S.
}

\begin{abstract}
The case notes of 34 patients undergoing rehabilitative facial nerve surgery between 1978 and 1994 were retrospectively examined. Thirteen patients underwent facio-hypoglossal transposition with six achieving a facial nerve grade of IV (House-Brackmann scale) at 24 months post-surgery. Twelve patients underwent cable grafting of the facial nerve defect. Of these, 10 achieved a grade III result at 24 months. Nine patients underwent end to end anastomosis of the facial nerve, seven achieving a grade III result at 24 months after the repair. Re-routing of the facial nerve and the use of tissue glue to effect the anastomosis did not have an adverse effect on the outcome. Comparison of rerouted end to end anastomosis with non-re-routed cable grafting showed no difference. Patients presenting pre-operatively with facial weakness and those in whom nerve repair surgery was delayed for more than six months were less likely to have a good result.
\end{abstract}

Key words: Facial paralysis; Facial nerve, surgery; Fibrin tissue adhesive; Hypoglossal nerve

\section{Introduction}

Since the initial description over 50 years ago of a successful intratemporal repair of the facial nerve (Bunnell, 1927) and his subsequent report of facial nerve grafting (Bunnell, 1937), physiological repair of the facial nerve has become an established surgical technique. Standardisation of the documentation of facial function using scoring systems such as the House-Brackmann Scale (House, 1983) has allowed comparison of techniques, outcomes and determination of prognostic indicators. The purpose of this study was to evaluate the results of facial nerve repair and nerve transposition undertaken in this department over the last 16 years.

\section{Patients and methods}

The clinical records of all patients who had undergone facial nerve surgery between 1978 and 1994 were retrospectively examined. General patient details such as age and sex were recorded. In addition, the following specific parameters were entered into the database: primary diagnosis, facial function at presentation (using the House-Brackmann grading system), primary surgery, facial nerve procedure (direct anastomosis, cable graft, faciohypoglossal transposition), re-routing of the nerve, and anastomosis technique. The timing of rehabilitative surgery was calculated with respect to the onset of the facial paralysis or loss of nerve integrity. The outcome of surgery was documented at six, 12 , 24 and 36 months post-operatively.

\section{Results}

General

Of the 34 patients studied, the age range was 19 to 69 years with a equal representation of males and females. Although the period of follow-up ranged from six months to three years, only the results for patients with at least one year follow-up were included for discussion. Three-year follow-up was available in 13 of the 34 cases but of these, only two patients demonstrated an improvement in their facial function between 24 and 36 months.

\section{Underlying pathology}

The types of underlying pathology in this series are summarised in Table I and the facial grade on presentation is shown in Table II. Patients with either a vestibular schwannoma or a glomus tumour had a more favourable outcome from facial nerve surgery than those with other underlying pathology but this is more likely a reflection of the fact that the latter group all had impaired facial function at presentation.

From the University Department of Otolaryngology, Manchester, UK.

This paper was presented by Mr S. R. Saeed at the 2nd International Conference on Acoustic Neuroma Surgery, Paris, April 1995 and formed a poster presentation at the 9th British Academic Conference in Otolaryngology, Manchester, July 1995.

Accepted for publication: 22 June 1996 
TABLE I

UNDERLYING PATHOLOGY IN THE PATIENTS UNDERGOING FACIAL NERVE SURGERY

\begin{tabular}{lc}
\hline Vestibular schwannoma & 18 \\
Glomus tumour & 6 \\
Petrosal cholesteatoma & 4 \\
Facial neuroma & 2 \\
Surgical trauma & 2 \\
Reparative neuroma & 1 \\
Synovial sarcoma & 1 \\
\hline
\end{tabular}

The predominant diagnosis of vestibular schwannoma reflects the increasing throughput of patients with this diagnosis.

\section{Type of rehabilitative surgery}

Thirteen patients underwent a facio-hypoglossal transposition, nine underwent end to end anastomosis (five of which involved re-routing of the facial nerve) and 12 underwent cable grafting (four with re-routing). The cervical plexus was the source of graft tissue in 10 of the 12 cable graft cases

\section{Facio-hypoglossal transposition}

Follow-up of at least one year was available in eight cases. Three patients achieved grade IV facial function at 12 months. This had risen to six of the eight patients by the end of two years postoperatively. In one patient, the surgery conferred no benefit, and none of the cases studied attained a grade III result (Figure 1).

\section{End to end anastomosis}

Seven of the nine patients in this group scored grade III facial function at two years and one of the seven went on to achieve grade II function (Figure 2).

\section{Cable graft anastomosis}

In this group, 10 of 12 patients attained grade IV

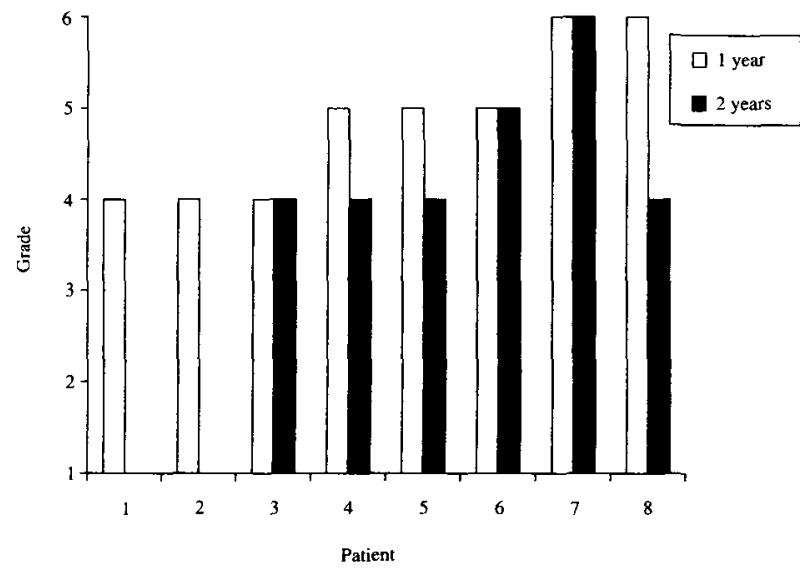

Fig. 1

Results of facio-hypoglossal transposition. The light bars represent facial function at one year with the dark bars representing facial function at two years post-surgery. Six of the eight patients in whom two year follow-up was available attained grade IV facial function
TABLE II

FACIAL FUNCTION AT PRESENTATION (HOUSE-BRACKMANN SCALE)

\begin{tabular}{cc}
\hline Facial grade & Number of cases \\
\hline I & 17 \\
II & 6 \\
III & 0 \\
IV & 1 \\
V & 3 \\
VI & 7 \\
\hline
\end{tabular}

Half the patients studied had normal facial function at presentation.

function at one year. By two years follow-up, 10 of the 12 patients scored grade III facial function (Figure 3). Two patients subsequently achieved grade II function at three years follow-up.

\section{Effect of re-routing of the facial nerve}

In the nine patients who underwent re-routing of the facial nerve prior to end to end or cable anastomosis, seven scored grade IV at one year. In the 12 patients without re-routing, nine attained grade IV function. No discernible difference between the two groups was thus shown (Figure 4).

Comparison of re-routed single anastomosis with non-re-routed cable anastomosis

Of the eight patients that underwent cable grafting without rerouting of the facial nerve, six attained grade III facial function at two years. Three of the six cases that underwent end to end anastomosis with rerouting of the nerve achieved a similar outcome.

\section{Anastomotic technique}

Of the 34 cases examined, details of the nerve anastomosis was available in 26 patients. These were equally divided between suture and fibrin glue anastomosis. Tissue glue was selected as an alternative to neural suture as the former is technically

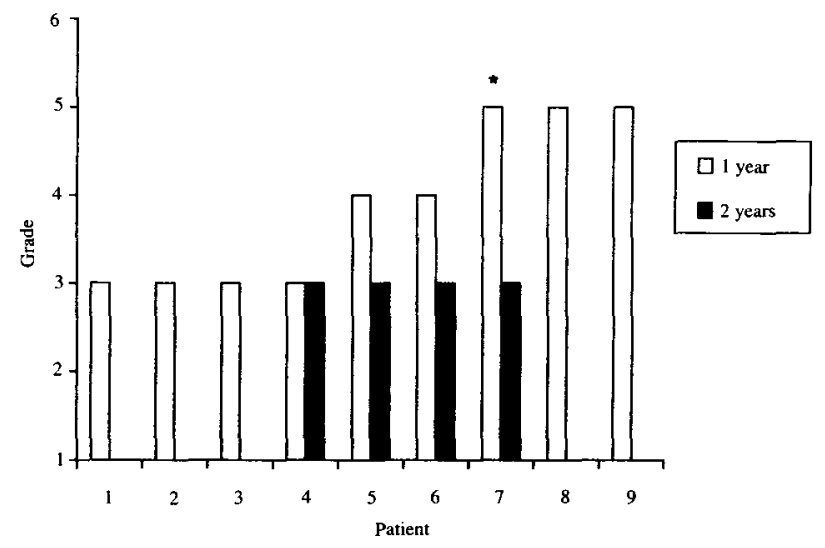

FIG. 2

Results of direct end to end anastomosis of the facial nerve. Two years post-operatively, seven of the nine cases achieved grade III facial function. *This patient subsequently attained grade II facial function. 


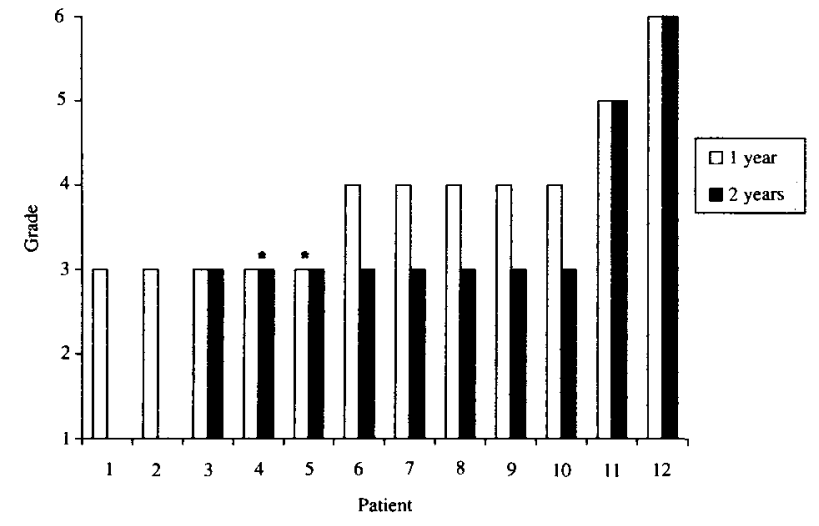

Fig. 3

Results of cable grafting of the facial nerve. At two years follow-up 10 of the 12 patients had grade III facial function. *These two patients subsequently attained grade II facial function.

easier. In both groups, eight patients achieved grade IV function or better at one year (Figure 5).

\section{Facial function at presentation}

Seventeen patients presented with normal facial function pre-operatively. Of this group, 14 had postoperative follow-up at one year with 10 patients attaining grade IV or better at 12 months. Of the 17 patients presenting with established facial weakness, 15 had one year follow-up with seven managing grade IV function or better at 12 months (Figure 6).

\section{Timing of surgery}

Of the 16 patients undergoing facial nerve surgery immediately or within six months, nine scored grade III function at one year. Five patients underwent surgery later than six months and none of these cases achieved grade III function.

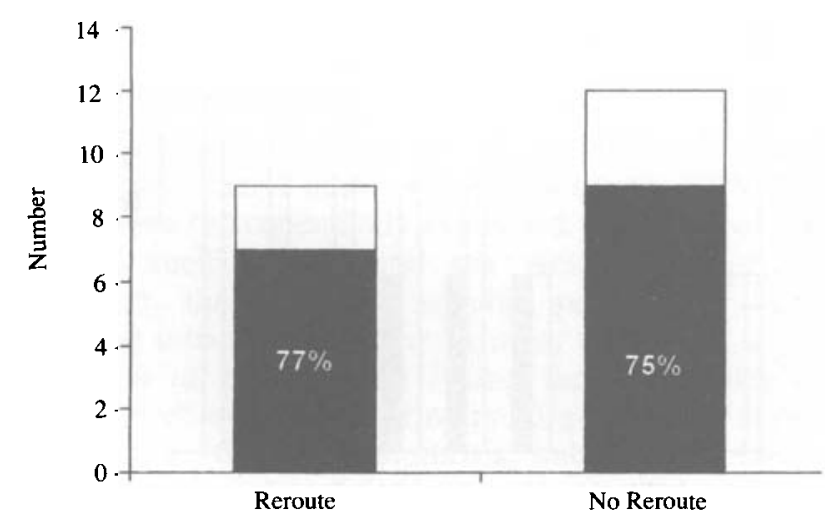

Fig. 4

Effect of re-routing of the facial nerve during reparative surgery. Seventy-seven per cent re-routed cases (seven of the nine) and 75 per cent non re-routed (nine of the 12) cases attained grade III facial function at one year.

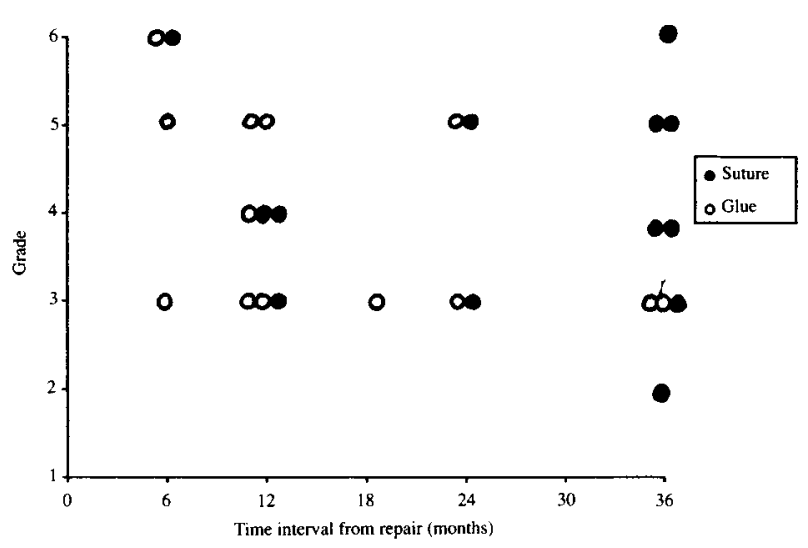

FIG. 5

Scatter plot comparing suture and fibrin glue nerve anastomosis. Each plot represents one patient. Of the 13 patients in each group, eight attained grade IV or better facial function at one year.

\section{Discussion}

Over the last three decades, advances in surgery of the posterior cranial fossa and craniobase have been paralleled by refinements in rehabilitative facial nerve surgery. Successive reports of the results of this type of surgery have generally been consistent in terms of facial outcome with the emergence of a number of principles (Barrs et al., 1984; Samii, 1984; Arriaga and Brackmann, 1992; Terris and Fee, 1993). If possible, loss of nerve integrity should be repaired immediately by way of direct anastomosis or cable grafting if the defect cannot be bridged after petromastoid re-routing of the facial nerve. Cervical plexus interposition is widely employed for this purpose but if greater than 12 centimetre lengths are required then the sural nerve is appropriate (Hoffman, 1992). Allowing for Wallerian degeneration and subsequent regeneration, recovery takes 12 to 24 months for a nerve repair in the cerebellopontine angle.

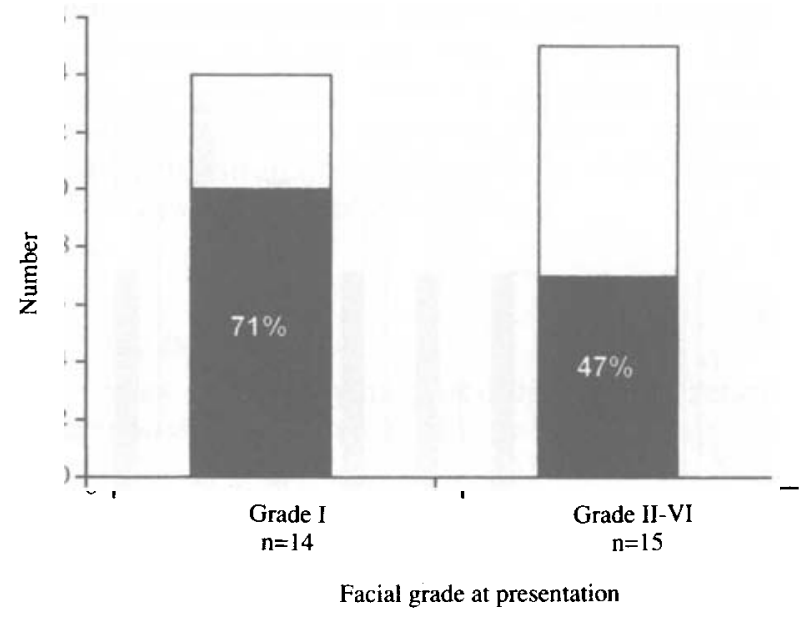

FIG. 6

Effect of facial function at presentation on the outcome of reparative facial nerve surgery. Seventy-one per cent of patients presenting with a normal face gained grade IV or better facial function at one year (10 out of 14). In those patients presenting with compromised facial function, less than half achieved a similar status (seven out of 15). 
Nerve crossover procedures were first described in the early part of this century (Hoffman, 1992). One of the largest series reported was that of Baker and Conley (1979) in which 137 patients undergoing facio-hypoglossal transposition were extensively followed-up. It is generally accepted that a period of 18 months should be allowed for spontaneous recovery before considering a transposition procedure. Our findings in this study suggest a delay of this magnitude might compromise the facial outcome. Electrophysiological studies may help in determining which patients require earlier intervention. Concerns about the effects of unilateral denervation of the tongue in facio-hypoglossal transposition have resulted in various modifications of the technique. One option is to undertake a partial hypoglossal transposition. More recently, May has described the hypoglossal-facial nerve interposition jump graft with encouraging results (May et al., 1991).

Findings in this study concur with the literature in that patients presenting with established facial weakness have a less favourable outcome than if facial function is normal at the outset, and that immediate or early facial nerve repair is more likely to give a favourable result.

Whilst the absolute numbers available for analysis were small, comparison of outcome in the re-routed end to end anastomosis cases with the non-re-routed cable graft patients showed no difference despite the latter group undergoing two anastomoses. Since rerouting of the facial nerve and subsequent anastomosis takes considerably longer than interposing a cable graft without re-routing, there seems to be a case for electing to undertake a cable graft when confronted with a situation where a deficient segment of nerve cannot be repaired by direct end to end anastomosis.

The use of tissue glue rather than neural suture to effect the anastomosis was not found to have an adverse effect on the outcome in this series. This finding has been substantiated by experimental work in the rat model (Murray et. al., 1993). Technically, a fibrin glue anastomosis is easier than suture repair, particularly in the posterior cranial fossa and the former technique is now used routinely in this department.

\section{Conclusions}

(1) Direct anastomosis or cable grafting of the facial nerve gives a superior outcome to VII-XII transposition in terms of facial function.

(2) If surgical repair of the facial nerve is under- taken at the time that nerve integrity is lost, a grade III or better outcome can be anticipated.

(3) Patients with compromised facial function at presentation have a less favourable outcome from rehabilitative surgery than if facial function is normal at the onset.

(4) Re-routing of the facial nerve during reparative surgery does not have an adverse effect on facial function outcome.

(5) Patients undergoing cable grafting without rerouting fared no worse than those undergoing end to end anastomosis with re-routing of the facial nerve.

(6) Tissue glue anastomosis is as effective as conventional neural suture. The former technique however is generally easier, particularly in the posterior fossa when the nerve is lost near the brainstem.

\section{References}

Arriaga, M. A., Brackmann, D. E. (1992) Facial nerve repair techniques in cerebellopontine angle tumor surgery. American Journal of Otology 13: 356-359.

Baker, D. C., Conley, J. (1979) Hypoglossal-facial nerve anastomosis for reinnervation of the paralyzed face. Plastic and Reconstructive Surgery 63: 63-72.

Barrs, D. M., Brackmann, D. E., Hitselberger, W. E. (1984) Facial nerve anastomosis in the cerebello-pontine angle: $A$ review of 24 cases. American Journal of Otology 5: 269-272.

Bunnell, S. (1927) Suture of the facial nerve within the temporal bone: With a report of the first successful case. Surgery, Gynecology Obstetrics 45: 7-12.

Bunnell, S. (1937) Surgical repair of the facial nerve. Archives of Otolaryngology 25: 235-259.

Hoffman, W. Y. (1992) Reanimation of the paralyzed face. Otolaryngologic Clinics of North America 25 (3): 649-667.

House, J. W. (1983) Facial nerve grading systems. Laryngoscope 93: 1056-1059.

May, M., Sobol, S., M. Mester, S. J. (1991) Hypoglossal-facial nerve interposition jump graft for facial reannimation without tongue atrophy. Otolarynglogy-Head and Neck Surgery 104: 818-825.

Murray, J. A. M., Willins, M., Mountain, R. E. (1993) The use of the rat facial nerve model to assess the effect of differing anastomotic agents on the facial nerve. Clinical Otolaryngology 18: 492-495.

Samii, M. (1984) Facial nerve grafting in acoustic neuroma. Clinics in Plastic Surgery 11: 221-225.

Terris, D. J., Fee, W. E. (1993) Current issues in the nerve repair. Archives of Otolaryngology, Head and Neck Surgery 119 (7): 725-731.

Address for correspondence:

Mr Shakeel R. Saeed F.R.C.S. (ORL),

University Department of Otolaryngology,

Manchester Royal Infirmary,

Oxford Road,

Manchester M13 9WL 